\title{
SEGUNDO INFORME DE LABORES DEL INSTITUTO DE INVESTIGACIONES ESTÉTICAS 1991-1992
}

\begin{abstract}
Sin temor a exagerar, y con el deseo de representar el estado de ánimo de todos los integrantes de este instituto - personal académico y administrativo-, puedo decir que estos últimos doce meses han sido de trabajo intenso y de crecimiento en distintas direcciones.

El número de investigadores ha aumentado y tenemos entre nosotros nuevos técnicos académicos. Estos jóvenes colegas ya nos benefician con su vitalidad y su trabajo, que se perfila promisorio y renovador. Bienvenidos sean todos los nuevos miembros de este Instituto.
\end{abstract}

\section{La investigación}

El año pasado, en ocasión del primer informe, intenté dar una definición amplia de nuestras disciplinas y hacer un pequeño resumen de la manera en que están integradas las áreas de estudio. Para este rubro fundamental, voy a intentar trazar ahora líneas de convergencia entre los distintos campos de especialización y no separarlos por periodo histórico, quizá para mostrar que, en distintos momentos, nuestros intereses y metodologías se cruzan.

Empezaré por decir que el área de arte prehispánico desde hace algunos años se ha fortalecido en la medida que sus metodologías se han diversificado. Por un lado, se ha consolidado un grupo que por la distinta formación profesional de sus miembros (historiadores, historiadores de arte, arqueólogos y restauradores) tiene una amplia perspectiva que ha abierto nuevos caminos para acercarse al complejo campo del arte precolombino. Por otro, trabaja en proyectos de investigación como el de la Pintura mural prehispánica, que refuerzan el vínculo con otras disciplinas: a las ya mencionadas se suman la arquitectura, la epigrafía y la astronomía. Otro proyecto, El h̆hule en la plástica mexicana, es un estudio de la significación ritual pero también material de este elemento, lo cual conlleva la aplicación de una metodología que recurre a la antropología, la biología y la química.

Por otra parte, en los últimos tiempos se ha iniciado la investigación de zonas hasta hace poco relegadas en los estudios mesoamericanos. Esto no sólo se advierte en el proyecto comprensivo de Pintura Mural Prehispánica, sino también en otros, como en el del Septentrión Mesoamericano, que se ocupa de lo que hoy son los estados de Zacatecas y de Durango, cuyo 
desarrollo cultural necesita esclarecimiento a partir de las fluctuaciones migratorias que tuvieron lugar en esas entidades. Estas fluctuaciones se revelan en los patrones de asentamientos, en la arquitectura y en el análisis iconográfico de la cerámica y los petroglifos.

El norte de México es, en el Instituto de Investigaciones Estéticas, objeto de estudio a distintos niveles. En el área de arte colonial se han desarrollado trabajos fundamentales sobre la arquitectura y otras manifestaciones artísticas que se hallan en esa zona. Entre otras cosas, esos estudios han incorporado a la historia del arte en una historia del trabajo, ya que el análisis estilístico requiere del conocimiento de los orígenes y procedencia de los artesanos y constructores envueltos en pequeñas y grandes edificaciones.

Los dos proyectos, prehispánico y colonial, han contribuido a establecer nexos con las universidades de Zacatecas, Durango y Ciudad Juárez, y confirmado el enorme interés que existe fuera del centro de la República por comprender la historia propia y las artes regionales. Por nuestra parte, ya hemos propuesto convenios con la provincia, y aunque los acuerdos han adelantado, aún no se consolidan. Quizá éste sea un buen momento para pedirle, señor coordinador, que se interese para que se hagan efectivos.

Ahora volvamos a las investigaciones que se realizan en el Instituto. La historia, como disciplina, ha sufrido cambios considerables en la última década. La idea de formular un marco teórico para poder iniciar una investigación, tan popular en los setentas, ha cedido ante la demanda de un conocimiento más concreto y también más vivo de los factores que intervienen en la vida de los pueblos; por ejemplo, el de la articulación de lo cotidiano en los espacios privados con los públicos.

En el Instituto actualmente se trabaja en varios proyectos sobre $e l$ arte $y ~ l a$ vida cotidiana. En el área de prehispánico las fuentes son las pictografías de los códices, en las cuales se analiza el lenguaje, el cuerpo y la gestualidad en distintos niveles como vía para hacer una interpretación de las características culturales y estéticas de los antiguos pueblos de México. Es decir, esta interpretación se hace tomando como base las figuras y el particular sentido de su narrativa, lo que permitirá definir sensibilidades desde las culturas originarias, separándose así de los criterios ajenos, en tiempo y mentalidad, a dichas culturas milenarias. Por otra parte, en esta tarea la frecuente carencia de datos confiables respecto a fechado y procedencia requiere instrumentos conceptuales estrechamente ligados a la observación y al análisis en el interior de las obras.

En el mismo tenor de observación interna de la obra de arte con objeto de acercarse a la intencionalidad artística prehispánica que subyace en el 
manejo de formas, color e iconografía, en esta área se realizan estudios desde la semiótica plástica de Greimas. Otros más analizan los signos como una estructura de lenguaje en la que hay que descifrar su combinación sígnica, que se extiende a la pintura y la escultura. Este conocimiento del lenguaje sígnico permite analizar y comprobar la extensión y los límites de una cultura determinada. Tal es la aportación del estudio que se realiza sobre el centro de Veracruz.

Por lo que toca al arte colonial y con miras a dar una interpretación de la vida cotidiana en los siglos xVII y xvIII, se ha iniciado la búsqueda de documentos en diversos archivos notariales de los inventarios de bienes. $\mathrm{El}$ estudio de estos documentos permite conocer qué clase de objetos integraron la cultura material doméstica de los habitantes del México virreinal, y para ello se han utilizado cartas de dote, testamentos, cuentas de división y participación de bienes y otros. De especial interés en esta investigación es la casa novohispana, su decoración interior, el ajuar doméstico, la vestimenta, el gusto artístico y el coleccionismo.

La vida cotidiana ha interesado también a investigadores del área de los siglos XIX y XX: por ejemplo, reunir la documentación, paso a paso, de una historia familiar que se ubica en una hacienda zacatecana desde su fundación hasta su desaparición. Este trabajo implica el seguimiento exhaustivo en archivos cuyos documentos permiten entender los regímenes de propiedad, la estructura familiar y otros muchos aspectos que, fincándose en lo cotidiano, explican la formación cultural de una región.

Los seminarios de área han reforzado metodologías o maneras de acercamiento a los problemas, propiciado el intercambio de puntos de vista y la revisión de fuentes antes no utilizadas para la historia del arte, como lo son los sermones y las imágenes religiosas en su contexto histórico y cultural, lo cual puede observarse en el dedicado al siglo XviII.

En este Instituto, la Ilustración en México es objeto de una reelaboración por medio de los estudios sobre arte. Varias investigaciones reconocen su impacto a través de las expediciones científicas enviadas a la Nueva España por los Borbones. La búsqueda de nuevos negocios por parte de la Corona Española amplió el conocimiento geográfico, étnico y de las costumbres durante el Virreinato. La Ilustración mexicana produjo la primera valoración del arte antiguo de México realizada por los jesuitas. Este primer reconocimiento del valor de las antigüedades mexicanas fue el signo de un cambio de actitud de los estudiosos occidentales ante las culturas indígenas de América.

El arte colonial es objeto de estudios monográficos exhaustivos y que son indispensables. Muestran estos estudios distintos métodos de análisis, 
entre ellos ubicar el rol social del artista en su coyuntura histórica y el seguimiento de un exhaustivo análisis iconográfico de las obras que dan un sentido que atraviesa el ámbito artístico y nos orienta hacia las especificidades culturales. Entre ellos podemos mencionar las investigaciones acerca de Tresguerras, Los hermanos Juan y Nicolás Rodríguez Juárez, Cristóbal de Medina Vargas Machuca y Juan Correa: este último es quizá el proyecto más extenso de este tipo y que requirió la colaboración de técnicos académicos.

En el área dedicada al siglo xx se han generado dos seminarios que no cuajaron con facilidad por la heterogeneidad de sus objetivos. Sin embargo, algunos investigadores hemos encontrado un proyecto en común con el seminario de videodisco del muralismo mexicano que se describe más adelante. Por otra parte, al igual que los otros seminarios, es el espacio para realizar una tarea de evaluación cualitativa que se inicia con un análisis de la producción individual y que continúa por la vía de las preguntas fundamentales acerca de la disciplina, como por ejemplo cuáles son los campos de estudio y las líneas metodológicas que marcan actualmente una renovación en la especialidad o qué diferencias específicas hay entre las investigaciones que se llevan a cabo en el Instituto y las de otros centros de investigación, nacionales e internacionales.

El seminario de siglo xx quizá sea el más heterogéneo porque en él participan las secciones de danza, cine, literatura y música. En danza y cine, a pesar de estar, una y otra especialidad, en manos de un solo investigador, se ha llevado a cabo una labor coherente y continua, que ha producido las primeras obras de investigación en su género y, en algunos aspectos, por la amplitud de su material documental, son trabajos definitivos.

En el área de música hay una reestructuración: por un lado está el trabajo teórico de composición de carácter interdisciplinario ligado al Instituto de Matemáticas Aplicadas y, por otro, la ampliación de su espectro histórico más alla de los siglos xIx y xx; hemos añadido también estudios de música para el periodo colonial.

\section{Investigación en archivos}

Como ya se habrá notado por lo dicho hasta aquí, en el Instituto se pone gran énfasis en la revisión de diversos archivos, con el fin de reunir material documental y hemerográfico que sirva de base a los distintos estudios a que se dedican los investigadores $y$, además, a aquellas otras personas que soliciten consultarlo. 
Desde luego, las tareas de rescate de documentos tienen distinta utilidad en áreas diferentes. Por ejemplo, en el área de arte moderno el término "for tuna crítica" significa entrar en el campo de la recepción, es decir, cómo un artista o conjunto de obras es percibido e interpretado por otra persona u otra cultura. En este sentido se realiza una vasta investigación sobre la "fortuna crítica" de los artistas mexicanos en los Estados Unidos, que redunda en un análisis de la interacción que se dio entre ambos países en el periodo comprendido entre 1920 y 1945 . Otro estudio en esta dirección se ha realizado en relación al movimiento surrealista en México, en especial en torno a la obra de María Izquierdo.

El Instituto publicó, hace varias décadas, tres volúmenes que llevan por título La crítica de arte en México en el siglo XIX, y ahora se proyecta continuar el mismo tema, de 1900 a 1920.

Por otra parte, en el área del xIx se han revisado gran parte de los archivos que se guardan en la Academia de San Carlos, trabajo que se propone conocer la historia de la educación en el campo de las artes plásticas y además interpretar el carácter de la producción de los artistas que allí se formaron.

En el campo de la arquitectura se realizan dos tipos de trabajo, uno de carácter teórico ligado a la ecoestética urbana, lo que implica el análisis multidisciplinario del entorno urbano y los problemas que éste genera, y otro, en cambio, está dedicado a hacer estudios sobre arquitectura del siglo xx y también a una extensa labor de recopilación de materiales sobre el tema.

La historia del arte de los siglos XIX y xx ha sido objeto de amplios y renombrados estudios en el Instituto de Investigaciones Estéticas. Para fortalecer esta contribución, hay un grupo de investigadores dedicados a su revisión y enriquecimiento a partir de una lectura diferente de estos temas.

Por otra parte, la historia del arte del siglo xx se ha transformado gracias a los estudios sobre modernidad que implican imágenes como testimonios de los mecanismos del Estado moderno. Tal es el sentido de nuevas investigaciones en el campo de la fotografía. Los enfoques de una historia social se han renovado al establecer un mayor equilibrio entre el análisis de la obra y las claves que encierra sobre la sociedad que la engendra.

Tenemos un proyecto en conjunto que atraviesa la pluralidad de nuestras especialidades: se trata de Arte mexicano en el mundo, registro y análisis; a partir de los límites indispensables, es un estudio sobre el arte mexicano de todos los tiempos que se encuentra fuera de nuestro país.

Todas las cosas hasta aquí dichas sólo comprueban que, si bien la especialización del Instituto gira en torno de las artes en México, la variedad de enfoques y metodologías es muy amplia. 


\section{Archivo fotográfico}

Es de sobra conocida la importante labor de apoyo a la investigación, la docencia y la difusión que desarrolla el personal técnico-académico del Archivo Fotográfico Manuel Toussaint, el cual se incrementó durante el año que se informa con 10,089 diapositivas en color, sumando con ello 203,204, y 1,618 negativos en blanco y negro para hacer un total de 104,816 . Cabe señalar que su acervo provee gran parte del material gráfico para las publicaciones del Instituto.

Se adquirieron 826 negativos en blanco y negro y 133 placas en color sobre artistas mexicanos y su obra, material fotografiado en la década de los cincuenta por Juan Guzmán.

De igual forma, se compraron 382 diapositivas de arquitectura colonial y del siglo XIX y de arte popular mexicano de la colección de Jesús Franco Carrasco (fallecido miembro del Instituto) y una serie de 72 diapositivas del antiguo Palacio de Comunicaciones, el Palacio Cantón y el mural La Creación de Diego Rivera, tomadas por el fotográfo Vicente Guijosa.

La fototeca obtuvo, una vez más, el apoyo de la Dirección General de Asuntos del Personal Académico para continuar el proyecto Monografías sobre Arte Mexicano, a fin de proseguir con la amplia tarea de su difusión, en este caso, a través de cuadernos de transparencias con su respectivo folleto explicativo.

Es necesario señalar que, gracias al apoyo económico del Consejo Nacional de Ciencia y Tecnología, se adquirió un equipo especializado que asegura una mejor y mayor conservación del material fotográfico: 14 estantes de acero esmal tado para el resguardo de diapositivas, un densitómetro para elevar la calidad de los negativos, 3 higrómetros para el control de la humedad y temperatura relativas, tanto para la bóveda como para el área del acervo.

En términos de actualización, los técnicos académicos de la fototeca tomaron varios cursos: uno de iluminación fotográfica, otro de densitometría, tres de diferentes programas de computación y tres sobre conservación y restauración de materiales.

Asimismo, los integrantes de la fototeca montaron, nuevamente, la exposición Xochimilco en imágenes, en la Delegación política del mismo nombre, que la solicitó debido al éxito que obtuvo en 1992. Cabe señalar que la fototeca contó con 15 estudiantes de la Facultad de Filosofía y Letras y de la Escuela Nacional de Artes Plásticas de nuestra Universidad que colaboraron en las tareas de clasificación y catalogación del material fotográfico para cumplir así con su servicio social. 


\section{Sección editorial}

Luego de quedar vacante por algunos meses la coordinación de esta Sección, por fin pudo ser adecuadamente cubierta. Tal vez, de todas las secciones, la editorial haya sido la que sufrió cambios más significativos en lo relativo a su estructura y organización.

A partir de febrero de 1992, después de un análisis sobre el estado de las publicaciones, se llevó a cabo un programa de trabajo que permitiera mejorar la calidad de nuestros libros, renovar su diseño, reducir costos y, sobre todo, acelerar el proceso de producción. Para empezar a trabajar bajo los lineamientos de este nuevo proyecto, nos tuvimos que enfrentar a las dificultades que representaba el rezago de numerosos libros, y gracias a un manejo conveniente hemos podido ver publicados algunos de ellos en el mismo año pasado.

Los textos que fueron aprobados por el Comité Editorial en 1992, e incluso algunos de 1991, empezaron a ser trabajados con este nuevo sistema que consiste, esencialmente, en trabajar por separado cada una de las diversas etapas del proceso editorial Por fortuna, este método ha probado rápidamente su eficacia, pues en un corto periodo los investigadores han podido observar la rapidez con que progresan sus textos para convertirse en libros.

Sólo esperamos que este sistema de organización que tan buenos resultados nos ha dado no se contraponga a la política administrativa que se establezca en el área de publicaciones.

Cabe también agregar que esta sección se ha enriquecido con el ingreso de nuevos elementos que prometen eficiencia y calidad en su desempeño, pero que aún son insuficientes para la carga de trabajo que pesa sobre ella.

La nota triste en este rubro continúa siendo la paupérrima distribución que tenemos de nuestros libros, tarea que nos sentimos incapaces de afrontar debido a que internamente no contamos con la infraestructura necesaria para subsanar el problema. Por ello, desearíamos que la Dirección General de Fomento Editorial nos apoyara en este sentido con mejores resultados.

\section{Biblioteca}

El año de 1992 fue de importantes logros para la Biblioteca Justino Fernández, después de haber llevado a cabo la reestructuración de las funciones técnico-académicas de su personal. 
Se subsanó el rezago de 5,650 volúmenes recibidos por canje y donación que no habían sido sometidos al proceso técnico respectivo. El incremento del acervo fue cualitativa y cuantitativamente considerable. Con el presupuesto asignado al Instituto en este rubro se adquirieron 429 volúmenes y se recibieron por canje y donación 305 títulos más. Asimismo, se continuó con la política de compras directas a universidades, editoriales y proveedores del extranjero. Se formaron dos secciones separadas de consulta: la de libros y la de hemeroteca, a la que se le destinó un espacio independiente que agiliza la consulta.

De esta forma se optimizó el espacio existente para ampliar y asegurar la capacidad del acervo para tres años más, aproximadamente, a fin de mantener actualizado el fondo de nuestra biblioteca, en tanto las prioridades y acciones de las instancias universitarias permitan la expansión del espacio que debe albergarlo.

Otro logro fue la entrada en vigor del Reglamento Interno de la Biblioteca, a partir de enero de este año, contando, desde luego, con la debida aprobación del Consejo Interno del Instituto.

Se realizó una autoevaluación de las necesidades y prioridades de la Biblioteca, de la que surgió la urgencia de levantar un inventario. En su primera fase se preparó el acervo revisando la colocación y el ordenamiento topográfico de todos los títulos, iniciándose así el cotejo de éstos con las tarjetas del catálogo topográfico. Cabe señalar que fue muy notorio el incremento de la base de datos de los registros extraídos de los catálogos de Exposiciones de Arte.

Paralelamente al desarrollo de la base de datos del acervo, aún en su etapa de conformación, se participa activamente en reuniones con el Grupo de interés en bases de datos sobre ciencias sociales y humanidades de la UNAM para diseñar políticas que normen la transferencia de información y buscar los apoyos para la producción en discos compactos de estas bases.

El personal técnico académico y administrativo de la Biblioteca asistió a varios cursos introductorios y especializados acordes con las necesidades dei área a fin de optimizar el proceso técnico del fondo bibliohemerográfico.

\section{Sección de cómputo}

Se impartieron numerosos cursos de computación al personal académico y administrativo del Instituto, que han dado ya sus primeros frutos. Además, algunos de los miembros que se beneficiaron con esos cursos brindan hoy asesoría a sus compañeros. 
A pesar de haber acrecentado el equipo de cómputo, todavía resulta escaso para cubrir las necesidades, en constante aumento, de las áreas de investigación y de apoyo del Instituto; principalmente para los proyectos "Videodisco sobre el muralismo mexicano" y para las tareas de edición.

\section{Sección de archivos y hemerotecas}

La dispersión en las tareas de esta Sección llevó al Consejo Interno del Instituto a reorganizarla y a elaborar un reglamento que coadyuve, entre otras cosas, a vincular directamente su trabajo con la investigación y a marcar las características de las labores técnico-académicas que deben inscribirse en ella.

Con el mismo propósito, se formó una comisión (integrada por cuatro investigador es representantes de los periodos del arte mexicano que requieren de los servicios de esta sección) para que trabaje paralelamente con los técnicos-académicos y se incorporaron dos miembros más para que se ocupen de las fuentes documentales de los siglos XIX y XX.

A pesar de las medidas que se han tomado para reforzar la Sección de archivos y hemerotecas, ésta necesita aún de cambios y transformaciones para consolidarse y así desarrollar todo su potencial en apoyo a la investigación.

\section{Difusión cultural e intercambio académico}

En el año que se informa, se celebraron convenios específicos de colaboración académica, tanto con instituciones de educación superior como del sector oficial, para desarrollar proyectos de investigación y actos académicos organizados por este Instituto.

Los convenios con Conacyt favorecieron, por una parte, la elaboración de un libro de texto sobre Arte prehispánico y la impartición de un Taller de teoría y crítica de arte a cargo de un especialista cubano y, por la otra, ayudaron a financiar la estancia de investigación de Stanton Catlin, profesor emérito de la Universidad de Syracuse, quien dictó el seminario Análisis contextual para la elaboración de un catálogo razonado sobre el muralismo mexicano.

Como lo señalé anteriormente, los convenios gestionales a través de la Dirección General de Intercambio Académico de la Universidad Nacional Autónoma de México para la realización de los proyectos El vastísimo obispado de la Nueva Vizcaya de Pedro Tamarón y Romeral e Investigaciones 
Arqueológicas en Hervideros, Durango, con la Universidad Autónoma de Ciudad Juárez y la Juárez de Durango, respectivamente, han sido evaluados y dictaminados favorablemente por la instancia legal de esta Universidad, así como aceptados en todos sus términos por las instituciones contrapartes. Su firma sólo depende de la agenda de trabajo de las máximas autoridades de cada una de las universidades interesadas.

Por otra parte, el Instituto se ha beneficiado desde 1991 con la visita de Georges Roque, investigador comisionado por el Centro Nacional de la Recherche Scientifique de París, Francia, con el objeto de que desarrolle el proyecto La estética del color, el cual dio como resultado la impartición, en nuestra sede, del seminario Teoria y ciencia del color, mismo al que se invitó a participar no sólo a los miembros de nuestro personal académico, sino a estudiosos de la Escuela Nacional de Artes Plásticas de la Universidad Nacional Autónoma de México, del Centro Nacional de Investigación, Documentación e Información de las Artes Plásticas del Instituto Nacional de Bellas Artes y de la Universidad Autónoma Metropolitana, Unidad Azcapotzalco, principalmente.

Cabe anotar que el Instituto de Investigaciones Estéticas ha desplegado ampliamente la difusión de sus áctividades académicas, al invitar a participar en ellas a especialistas de otros centros e institutos de investigación, lo que sin duda enriquecerá los trabajos de cada uno de los estudiosos y el intercambio académico entre ellos, al mismo tiempo que redundará en beneficio de sus propias instituciones.

Por otra parte, el Instituto decidió organizar en esta ocasión, en la ciudad de México, su xvi Coloquio Internacional de Historia del Arte titulado El arte y la vida cotidiana, que se realizó del 9 al 11 de noviembre en el auditorio de la Coordinación de Humanidades de la UNAM, a fin de brindar, sobre todo a los estudiantes de las Facultades de Filosofía y Letras, de Arquitectura y de la Escuela Nacional de Artes Plásticas de la unam, la posibilidad de asistir, sin hacer grandes esfuerzos económicos, a un foro en el que se analizaron, en torno a un tema central, diversas interrogantes de la Historia del Arte Mexicano.

Es importante señalar que el Instituto apoyó la participación de ocho investigador es que impartieron cursos en diversas universidades de Estados Unidos. Baste como ejemplo el Seminario de Arte Colonial Mexicano que se realizó conjuntamente con la Universidad de Nuevo México, del 22 de junio al 2 de agosto de 1992, para profesores de diversas universidades de dicho país.

Al terminar de mencionar las distintas áreas del Instituto a cargo de los técnicos académicos, quisiera hacerles saber que en el Instituto apreciamos 
en todo lo que vale su profesionalismo y su gran sentido de responsabilidad. Sabemos que el Instituto no sería lo que es sin su labor fundamental.

El recuento de las actividades que el personal académico desarrolla a manera de cursos impartidos en provincia y en el extranjero es significativa, y lo mismo la enorme tarea de difusión que se realiza en distintos medios como lo son conferencias, artículos de divulgación y presentación de libros. Muchos miembros del Instituto están conectados con los departamentos de investigación de los museos y son claves para el éxito de buena parte de las exposiciones de calidad que se hacen en México.

En el programa de estímulos a la productividad académica participa el $55 \%$ de los miembros del personal académico de este Instituto. En cuanto al SNI, 25 miembros pertenecen al Sistema Nacional de Investigadores, lo que equivale a un $60 \%$. Hay miembros del Instituto que por sus méritos académicos podrían estar en el sNi con un alto nivel; sólo que encuentran este Sistema adverso y contrario a su manera de trabajar. Éstas son excepciones, pero su punto de vista debe ser respetado. Finalmente, por ellos habla el espléndido trabajo que realizan.

Es necesario señalar que, por el estrecho vínculo que existe entre docencia e investigación, 24 académicos, mayoritariamente investigadores, impartieron cursos en la licenciatura de Historia y en el posgrado de Historia del Arte en la Facultad de Filosofía y Letras principalmente, y además en las Facultades de Arquitectura y de Ciencias Políticas y Sociales, en la Escuela Nacional de Artes Plásticas y en el Centro de Enseñanza para Extranjeros de la UNAM. De igual manera, son docentes en otras instituciones de enseñanza superior como la Universidad Iberoamericana.

\section{Seminario de la Conservación y Restauración del Patrimonio Artistico y Monumental}

En 1991 se constituyó en el Instituto de Investigaciones Estéticas este Seminario con la idea de reunir a un grupo interdisciplinario e interinstitucional que iniciara, sobre la amplia experiencia de cada uno de sus miembros, un trabajo sistemático de reflexión sobre los diversos problemas teóricos y prácticos que generan el estudio, la protección y la salvaguarda del patrimonio artístico y monumental.

Por esta razón, el pleno del Seminario decidió organizar, el 29 y 30 de septiembre y el $1^{\circ}$ de octubre de 1992, su Primer Coloquio para demostrar que, aunque los intereses son diversos, los unifica la honda preocupación por los avatares del patrimonio artístico en un mundo en profunda transformación. 
La realización del Primer Coloquio dio voz a las inquietudes y preocupaciones de todos aquellos estudiosos interesados en la defensa, conservación y salvaguarda del patrimonio de nuestro país y se convirtió en un foro que llenó el vacío existente para manifestar las abundantes y constantes agresiones que sufre el patrimonio artístico nacional.

De igual forma, las disertaciones que se presentaron en el Primer Coloquio señalaron la falta de políticas adecuadas para la ejecución de acciones concretas encaminadas al rescate de nuestro patrimonio, y la urgencia de diseñar nuevas y creativas estrategias que sean capaces de enfrentar los problemas que lo afectan, no sólo en sus aspectos técnicos y artísticos, sino en cuanto a su legislación y administración.

\section{Videodisco sobre el muralismo mexicano}

Este año, el proyecto del videodisco interactivo sobre el muralismo mexicano ha llegado a consolidarse en su aspecto académico a través de un seminario integrado, en su mayoría, por investigadores y técnicos académicos que se ocupan del estudio del arte del siglo $\mathrm{xx}$, los cuales han elegido como tema central los murales de la Secretaría de Educación Pública y todo el contexto cultural y sociopolítico que gira en torno a su creación.

Gracias al afortunado apoyo de la Dirección General de Asuntos del Personal Académico, el proyecto podrá avanzar en forma significativa durante 1993.

\section{Videos sobre arte mexicano}

Los videos sobre el nacionalismo y la catedral metropolitana son el primer resultado de este proyecto, que pretende cubrir temas monográficos importantes de la producción artística mexicana.

Actualmente, se trabaja sobre los guiones de la Academia de San Carios y Teotihuacán, los cuales se concluirán este año.

A pesar del interés que la administración central universitaria mostró en un primer momento, los problemas de financiamiento no han podido ser aún superados.

\section{Laboratorio de diagnóstico de obras de arte}

Después de haberlo pensado y propuesto durante mucho tiempo, el 15 de octubre de 1992 se creó, junto con el Comité Mexicano de Historia del 
Arte, este laboratorio. Desde entonces a la fecha se han recibido una respetable cantidad de solicitudes para verificar la autenticidad de obras de diversas épocas, estilos y procedencias. El crecimiento es sostenido, nos estamos dando a conocer y, en términos generales, el laboratorio ha sido un éxito y tiene un futuro promisorio. Se ha creado para establecer una norma que contrarreste en la medida de lo posible las falsificaciones y todos los asuntos que rodean a las obras de arte cuando están ligadas al mercado.

En él participan, principalmente, los miembros del Instituto de Investigaciones Estéticas y del Comité Mexicano de Historia del Arte, además de reconocidos especialistas en la crítica y curaduría de arte.

\section{Premios y distinciones}

En el mes de noviembre, Beatriz de la Fuente y Jorge Alberto Manrique fueron honrados con el Premio Universidad Nacional 1992 en Investigación y Docencia en Humanidades, respectivamente. Por su parte, Óscar Olea fue distinguido con la medalla de Oro, que le otorgó la Federación de Colegios de Arquitectos de la República Mexicana.

Durante 1992 el Instituto recibió a dos investigadores españoles, uno del Centro de Estudios Históricos del Consejo Superior de Investigaciones Científicas, en Madrid, y de la Facultad de Ciencias Humanas de la Universidad de Jaume, así como a una especialista cubana del Centro Wifredo Lam de Cuba, para recibir asesoría académica y apoyo bibliohemerográfico y fotográfico de nuestra institución.

De igual forma, seis investigadores extranjeros impartieron sendas conferencias sobre arte universal; tal es el caso del reconocido historiador y crítico de arte canadiense de la University of British Columbia, Serge Guilbaut.

Un investigador y un técnico académico obtuvieron la beca a hispanistas extranjeros que otorga el Ministerio de Asuntos Exteriores de España.

Además, tres investigadores contaron con el apoyo de este Instituto y la Dirección General de Intercambio Académico para llevar a cabo estancias de investigación en diversas ciudades europeas (Varsovia, Madrid, París), con objeto de continuar las indagaciones sobre su tema central de estudio.

Ha sido un año de satisfacciones pero también hemos sufrido tristezas: dos compañeros, José Guadalupe Victoria y José Luis López Reyes, murieron aún jóvenes y también falleció Don Luis Cardoza. Recordamos a José Guadalupe y a Don Luis con dos homenajes. 
Además de haber hecho este reporte general de nuestras actividades, deseo añadir una reflexión que recoge los modos de pensar de muchos miembros del Instituto de Investigaciones Estéticas.

La Universidad está atravesando por procesos de cambio que, orientados con inteligencia y un agudo sentido crítico, serán benéficos para la Universidad en general y para Estéticas en particular. Este Instituto, debe decirse, está bien preparado de generaciones atrás para enfrentar una reorientación de los muy en boga procesos de evaluación, que se manifiestan aún inmaduros en Programa de Estímulos y Productividad Académicos y Sistema Nacional de Investigadores. La Coordinación de Humanidades, en épocas recientes, ha entendido la importancia de contribuir a este debate, el de la evaluación, a partir de sus especificidades.

¿Por qué digo que el Instituto tiene condiciones óptimas para enfrentar esta tarea? La respuesta está en la solidez de sus organismos colegiados: el Colegio de investigadores, el Consejo interno y el editorial tienen una tradición de décadas; sus reuniones ocurren con un ritmo regular e inviolable; no hay plaza, promoción o libro que se edite sin una evaluación rigurosa, lo cual no impide que estemos afinando criterios constantemente. En este sentido, hemos iniciado un proceso nuevo, producto de previas discusiones en el Colegio de investigadores y cuya implementación se practica en los seminarios de las distintas áreas; proceso que intenta trabajar con una definición de criterios cualitativos, ya que nos amenaza y daña una avalancha de fórmulas cuantitativas que, como todos sabemos, cumplen una etapa necesaria; pero si la Universidad ha de elevar su nivel académico por su comprensión de lo que es el conocimiento, debe orientarse hacia la convicción de que los criterios cualitativos no han de ser sacrificados en aras de una falsa homogenización de aquél. Esto quiere decir, en palabras llanas, que sólo aceptando y respetando el campo propio de las distintas disciplinas puede realmente hablarse de criterios cualitativos.

La autoridad moral que tenemos para decir esto, y sólo quiero ser la voz de mis compañeros, deriva de una tarea colegiada que cumple con creces sus funciones. La posición adoptada por otras comisiones evaluadoras que están por encima de nuestros cuerpos colegiados, y en éstos incluyo a la Comisión Dictaminadora, no emerge de un conocimiento de la trayectoria de algunos institutos, sino de desórdenes en algunas instancias que no han establecido el funcionamiento riguroso de su gobierno interno. Estamos plenamente convencidos de que la única y verdadera evaluación de lo que hacemos sólo puede discutirse entre pares. De otra manera, las horas y la energía que empeñamos en este proceso sólo serán recursos desperdiciados. No sabemos lo que contemplan las reformas al Nuevo Estatuto del Personal 
Académico; por lo pronto, nos regimos por el existente y en él no hay instancia por encima de los cuerpos colegiados.

El nuevo proceso de evaluación en el que nos hemos embarcado, no sólo está dirigido hacia afuera; lo que nos motiva es la superación interna y hacer un balance de las aportaciones del Instituto en el campo de los estudios sobre arte. Desde luego, ese balance arrojará faltas, carencias, áreas descuidadas, comparación de metodologías con otros estudiosos y otros modos de acercarse a la disciplina. La evaluación no sólo cuidará del trabajo de investigación; también de la vida que genera alrededor de ella: formación de estudiantes, actitudes frente a la docencia, participación activa en el posgrado de Historia del Arte. Si no fuera por los miembros de este Instituto, no habría Doctorado en Historia del Arte; no necesitamos ni queremos formar un sistema paralelo de posgrado en el Instituto porque estamos plenamente ligados a la Facultad de Filosofía y Letras y creemos que ahí es donde debe hacerse el trabajo de posgrado.

Este proceso de evaluación se contempla a corto y a largo plazo. A medida que tengamos propuestas concretas, se presentarán a la Coordinación, con el convencimiento de que podemos contribuir con nuestros puntos de vista al fortalecimiento de las Humanidades. No pensamos que las humanidades en México estén débiles intrínsecamente; se trata de un proceso de deterioro que viene de afuera. Si nos preguntáramos por las contribuciones que han hecho a la sociedad, diríamos que han desempeñado un trabajo fundamental en nuestro pais. Una simple revisión de nuestra memoria histórica mostraría que la cultura moderna en la que aún nos apoyamos se gestó gracias a un grupo excepcional de humanistas que creyeron en una educación integral, en la que el arte tiene un lugar indispensable para la formación de la identidad nacional, que no consiste en falsos espejismos de lo que somos, sino en una autoconciencia, en un descubrimiento de lo que nos es propio. En los tiempos que enfrentamos, la Universidad debe contribuir al debate de la integridad cultural y considerarla una prioridad.

Ha sido un año de intenso trabajo; nos recompensa ver al Instituto con una vida académica plena y una actitud consciente frente a los problemas de la Universidad No podríamos funcionar sin la dedicación de todos los Jefes de Área y sus excelentes colaboradores; me refiero a la Secretaría Académica, a la Secretaría Adminstrativa y a Intercambio Académico: todos trabajan muchas veces más allá de horarios y obligaciones.

Publicaciones, Fototeca, Biblioteca y Cómputo tienen una coordinación ejemplar.

El personal administrativo ha mostrado su eficiencia y buena disposición.

Nuestra disciplina tiene cada vez más una enorme demanda: ahí en provincia, donde las nuevas universidades abren carreras técnicas y adminis- 
trativas que desde luego son necesarias, nos demandan permanentemente conferencias, diplomados, intervenciones de distinto tipo.

Es importante dar una muestra del carácter interdisciplinario de las investigaciones en el Instituto para recalcar lo artificial que resulta la división que han asumido los Consejos Académicos de Área, las llamadas Ciencias Sociales por un lado y las Artes y las Humanidades por el otro. Esto sólo refleja el vasto desconocimiento que hay en la Universidad sobre los estudios de arte, que, por el alcance de su objetos de conocimiento, interactúan y necesitan de un amplio espectro disciplinario.

Es imposible no agregar que, mientras se fundan en provincia nuevas instituciones de educación superior que sólo promueven las llamadas carreras prácticas como la Contaduría y la Administración y se dejan de lado las Humanidades, origen de toda Universidad que se respete, la enorme demanda que tienen los investigadores de este Instituto para atender las necesidades que se manifiestan en la llamada provincia mexicana con relación a las artes sólo demuestra que la desvalorización de las Humanidades obedece más a un proyecto político en el que se encuentra inmerso nuestro país, que a un consenso de los distintos sectores sociales o de las instituciones dedicados a estos proyectos.

Maestra Rita Eder

DIREGTORA 